\title{
ECONOMICAL EVALUATION OF LOGISTICS CENTRES ESTABLISHMENT
}

\author{
Ieva Meidutè \\ Dept of Transport Management, Vilnius Gediminas Technical University, \\ Plytinés g. 27, LT-10105 Vilnius, Lithuania.E-mail: jevame@ti.vtu.lt
}

Received 14 December 2006; accepted 1 February 2007

\begin{abstract}
This paper presents a method for assessing the financial viability of a new Freight village financed by private and public investments. The financial evaluation model constitutes four distinct phases, namely (a) site selection and traffic forecasts, (b) definition of services offered and corresponding dimensions, (c) estimation of investment and operation costs and (d) evaluation of investments. Furthermore, the model produces financing scenarios, based on combinations of public and private funds.
\end{abstract}

Keywords: Logistics center, evaluation, intermodal transport, multi-modal transport.

\section{Introduction}

In recent years a speedy process of globalisation, elimination of border crossing and customs inspection procedures as well as other international business facilitation procedures have been taking place in the world. The transport sector and the transport infrastructure meeting the current needs constitute one of the key elements that can ensure the ultimate implementation of these processes. Therefore, it is of special importance to have a well-developed road network, a sustainable transport system and to be geared towards the latest tendencies of the international business, i.e. establish logistics centres together with a well- developed structure of cargo transport terminals $[1,2]$.

In the framework of the on-going economic, political, technical and technological developments within the transport sector, logistics centres are gaining a gradually increasing significance, as the concept of a logistics centre itself is based on the following three rather important elements: territorial planning that covers in parallel rationalization of its infrastructure, quality of transportation services and inter-modality development.

This concept is consistent with key global tendencies within the transport sector; therefore, establishment of logistics centres is given a special attention. Currently, the European Logistics Association (freight villages) includes 57 transport and logistics centres located in eight states (Italy, Spain, Germany, Denmark, Portugal, Luxemburg, Greece and France) and unites about 1200 transport operators.

The EUROPLATFORMS EEIG Report for 2004 presents the definition of a logistics centre, where a logistic centre is the hub of a specific area where all the activities relating to transport, logistics and goods distribution - both for national and international transit - are carried out, on a commercial basis, by various operators.

The operators may be either owners or tenants of the buildings or facilities built there. In order to comply with free market rules, a logistics centre must be accessible to all companies involved in the activities set out above [3, 4].

The logistics centres must also be equipped with all facilities necessary for carrying out the abovementioned operations. If possible, it should also include public service for the staff as well as users ' equipment. In order to encourage intermodal transport the logistics centres should preferably be served by a variety of transport modes (roads, rail, sea, inland waterways, air).

However, the potential customers of LCs, evaluate whether such integrated transport chain produces costssaving, enhances reliability, decreases transit time and improves quality [5]. Therefore, the customer is the real decision maker for the operators and the others are merely executing the orders [6].

It is vital that a Logistics centre be managed by a single and neutral legal body (preferably by a PublicPrivate-Partnership) if synergy and commercial cooperation must be ensured $[7,8]$.

\section{Investment facility}

Usually, if a Logistics center confirms to be viable for private investments, a legal entity is formed (with private and/or public funds of the joint venture type Public-Private-Partnership (PPP) scheme) that acquires the necessary land, constructs, operates and manages the Logistics centre. Also, it is charged with negotiations and agreements with the companies, which are interested in their eventual establishment in the Logistics center. 
Therefore, the financial evaluation of a new Logistics centre is mainly performed based on the viewpoint (and interests) of the private investor. The return on the private sector investment is the major criterion for assessing the feasibility of a project financed by private and possibly public limited companies, provided that the projects are beneficial for the society [9].

Any financial cost-benefit analysis for the estimation of the return on investment depends on the variable and fixed costs, as well as the revenues of the Logistics centre. Any revenue of the Logistics centre is dependent on the location and operation of various companies, their particular commercial relationship with the LC, as well as the use of the services offered.

Generally, investment decisions on infrastructure projects are made by the public sector based on socioeconomic evaluation. However, PPP type projects need financial evaluation that takes into account uncertainties and the resulting risks [10].

The common methods of incorporating risk in capital investment decisions are the dual risk-return and the risk adjusted discount methods. However, most methods assume that the cash flows of the project are certain, although it is well known that actual cash flows could differ substantially from the forecasted ones [11].

Some have introduced methods to overcome this drawback, like the value at risk systems that comprise the Adjusted Present Value (APV) and Net Present Value (NVP) at risk [12].

\section{The Framework of Logistics center}

\subsection{Site selection and traffic forecasts}

In this subsection a site selection is done at two steps: one at a "macro-level" and the other at the "micro-level".

The site identification at the macro-level is the choice of a location with no specific land boundaries, but only a broad area, usually identified with a name of a nearby locality. This is necessary for estimation of the traffic to be attracted by the Logistics center.

Once the traffic forecasting is done, and then the site selection at the micro-level follows. It is concerned with determination of the land boundaries of the Logistics center and it is usually done by means of wellestablished methods of site selection, employing in some cases multicriteria analysis.

As for the forecasted traffic to be attracted by the Logistics center, this is estimated with the application of appropriate models [13]. However, in order to apply these models an assumption about the costs of the services provided by the Logistics center is needed.

\subsection{Definition of services offered and corresponding dimensions}

Once the commodity type's volumes to be attracted by the Freight village are estimated, a number of various services to be offered can be determined. They are related to warehousing and storage, parking areas, rail/road terminal and needed equipment, loading/unloading, administration, customs, medical servi- ces, banking, food and lodging, gas refuelling, vehicle maintenance, container maintenance, security, etc. There are numerous European projects that determine such needs [14-16], whereas the IQ [17] research project provides a good overview.

Hence, based on values provided by the above studies/research, the required services and the corresponding size of the areas and the dimensioning of buildings, equipment as well as other items can be determined. Hence the model is developed that combines the estimated traffic with the needed surface and the required services. To determine the latter, assumptions about the following parameters are needed:

- ratio of weight/volume for each type of goods;

- accepted minimum height of stowage for each goods/transport unit;

- average time when the various goods categories remain in the Logistics center. studies.

The first parameter can be provided by relevant

The second parameter is dependent on the type of loading unit used (swap bodies that cannot be stacked, containers that can be stacked) or bulk goods that need other types of storage facilities.

The technical parameters for such designs are well established.

Finally the last parameter can be assessed from other Logistics centre performances [18] or derived from a short and simple market surveys.

Consequently, the surface $S_{j}$ needed for service $j$ (e.g. warehousing and storage) corresponding to goods of goods $i$ is estimated by the equation (1):

$$
S_{i j}=f\left(T_{i}, Q_{i j}, C C_{i j}\right)
$$

where: $S_{i j}$ - needed surface for service $j$ for goods $i$; $T_{i}$ - daily traffic of the goods $i$, in tonnes per day; $Q_{i j}$ - average time to provide the service $j$ to commodity $i ; C C_{i j}$ - other characteristics of the goods $i$ related to the provided service $j$.

Finally the needed surface $S_{j}$ for service $j$ is the summation of surface per goods:

$$
S_{j}=\sum f\left(T_{i}, Q_{i j}, C C_{i j}\right)
$$

As an example, the equations that provide the needed surface for warehousing and storage is presented

$$
S s_{i}=T_{i} t_{i} e_{i} H_{i}
$$

where: $T_{i}$ - daily traffic of the goods $i$, in tonnes per day; $t_{i}$ - average time when goods $i$ usually remain in the warehouse area; $e_{i}$ - the ratio of volume per weight of the goods $i$, in $\mathrm{m}^{3} /$ tonne; $H_{i}$ - the usual height of stowage of the goods $i$ in warehouses, in $\mathrm{m}$.

Applying this formula for all $(v)$ types of goods, the total surface needed for warehousing and storage is:

$$
S s=\sum_{i=1}^{v}\left(T_{i} t_{i} e_{i} H_{i}\right) \text {. }
$$


Therefore by applying the model of surface estimation, outputs are produced related to:

- total surface and height of storage and warehousing covered areas;

- total surface of open - air areas;

- total surface of parking areas;

- size of administrative buildings;

- surface of rail/road terminal and transhipment area;

- number and capacity of various loading/ unloading equipment;

- total length of internal road network and connection to the main road network;

- total length of internal rail network and connection to the main rail network;

- total length of other technical infrastructure (electricity, telecommunications, sewage).

\subsection{Estimation of investments and operation costs}

On the basis of the results of subsection 3.2, the following investment cost items are estimated:

- land acquisition cost;

- total construction cost and;

- equipment acquisition costs.

These cost categories are classified as fixed costs in the evaluation methodology.

The real estate cost is defined according to the current market unit prices ( $€$ /square meter).

The estimation of construction costs is based on observed unit prices in other similar construction projects and they are grouped into construction costs for land development, buildings, transhipment terminal, acquisition of equipment, etc.

In addition to these fixed costs, there are variable costs that are related to the operating expenses of the several facilities in the Logistics center. They are termed variable, since they are dependent on the volumes of using the facilities/services.

The total of the above costs - on an annual basis $C_{m}$ (for year $m$ ) will be used for the financial evaluation.

In the case of the expected final construction cost of the project, it is assumed:

Initial cost $=X_{a} \cdot$ surface of Logistics center,

where: $X_{a}-$ a unit cost in euro/m $\mathrm{m}^{2}$ of surface.

\subsection{Evaluation}

The evaluation stage comprises two distinct and complementary approaches:

- the financial and the socio-economic evaluation.

- the necessity for two parallel approaches derives from the very nature of a PPP. The achievement of an agreement between a public authority and a private investor depends on various factors, due to the fact that each member has different incentives and expects different kinds of benefits [18].
The private investor aims at increasing the return on investment. On the contrary, the public authority aims at increasing the benefits for the society and implementing its wider policy and plans. In order for an agreement to be reached between the two actors, it is essential for both to comprehend the specific requirements and to conclude a contract, which will satisfy their pursuits with the best possible way.

Therefore, the financial evaluation examines the private investor's interest and the socio-economic evaluation examines the public interest. Specific socioeconomic evaluation methods can be used on the basis of cost-benefit and/or multicriteria analysis [19].

A co-funded (PPP) project involves an interrelation process between private and public sectors, as shown in Fig 1.

At the left side of the figure the decision process by the public authority to go ahead or not with the project is presented. The public authority performs (with its own values for the variables) the socio-economic evaluation and a sort of financial evaluation. Based on these results, a decision is taken.

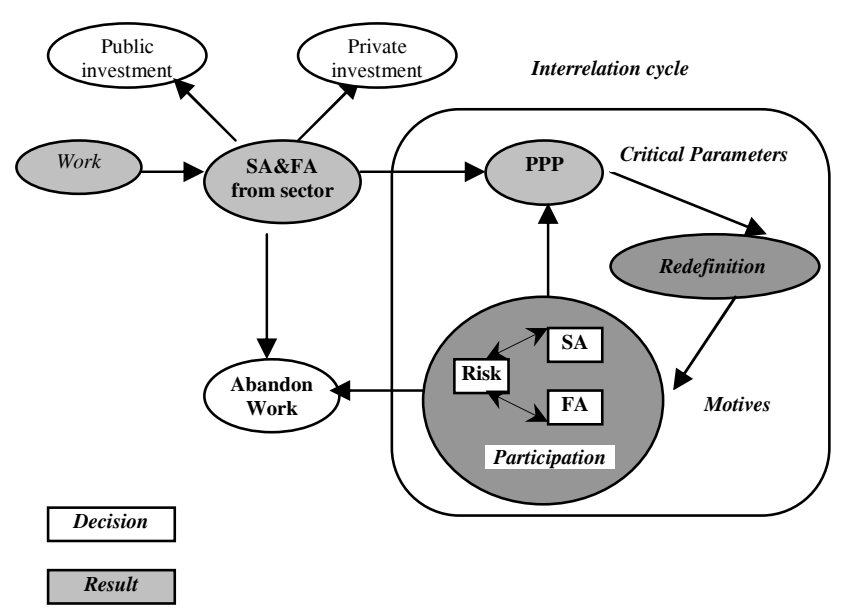

Fig 1. The interrelation process in co-funding projects on a PPP basis

The right side of the figure presents the process to be followed for a PPP project, once the public authority launches the project. It shows the interactive process between the public and private bodies in determining the acceptable (by both) conditions for the PPP scheme. The presented methodology in this paper is addressing to this process.

According to the results of these parallel methods, the following cases could arise:

\section{- Case 1:}

FA (Financial analysis results, e.g. return on investment) LESS THAN the acceptable limit (according to a rate of return, which has to be higher than the best rate in the market), and

SA (Socio-economic analysis results, e.g. IRR or NPV for national economy) GREATER THAN the acceptable limit (according to the internal rate of return, which has to be higher than the opportunity cost of capital or NPV $>0$ ). 
In this case the project may be taken over by the government or co-financed by a private investor under certain requirements.

- Case 2:

FA $>$ acceptable limit and SA $>$ acceptable limit.

In this case the project can be financed either by the public or by the private sector. It is an advantageous case for PPP.

- Case 3:

$\mathrm{SA}<$ acceptable limit.

In this case, the project cannot be realized, even though its financial evaluation is encouraging.

Assuming that the socio-economic evaluation produces positive results for the national economy (including the consideration of external costs, as environmental impacts and other social related costs) then the financial evaluation (appraisal) is necessary to assess whether PPP schemes are possible.

\section{Financial evaluation}

The financial evaluation process is described in Fig 2, where the steps followed and the variables considered are shown.

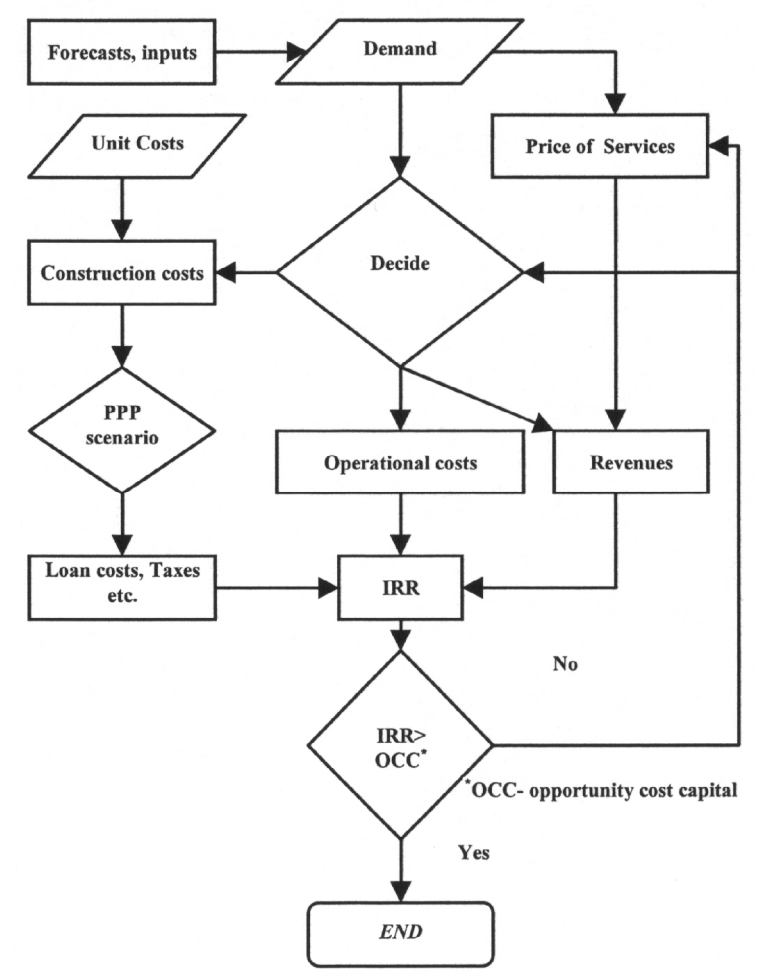

Fig 2. Financial evaluation process for each financial scheme

Primarily, the alternative scenarios of funding schemes have to be introduced. The alternative scenarios derive from various combinations of three funding sources:

- private investors (equity),

- bank loans,

- public institution.
Therefore, four general funding schemes are possible for the development of a PPP in the Logistics center:

- combination of private investments, bank loans and public institution or public limited company's funds;

- combination of private investments and bank loans;

- combination of private investments and public institution or public limited company's funds;

- fully private investments.

For each combination, the Internal Rate of Return (IRR) of private funds (equity) is calculated. It is an important indicator of the private sector's willingness to invest.

The first criterion for the choice of the appropriate investment scheme is the IRR. It is well established that the IRR must be greater than the opportunity cost of capital, or in other words - the most profitable risk-free investment, otherwise the investment is not viable and as such is not worth considering. The IRR of a capital budgeting project is the discount rate at which the NPV of a project equals to zero:

$$
\begin{aligned}
& N P V=0=\sum_{i=0}^{t} \frac{C F_{t}}{(1+I R R)^{t}}=C F_{0}+\frac{C F_{1}}{1+I R R}+\ldots+ \\
& \frac{C F_{t}}{(1+I R R)^{t}}
\end{aligned}
$$

where: $C F_{t}$ - the cash flow at time $t$.

In addition to this criterion, in order to safeguard a positive return every year, the net cash flow (annual revenues-annual expenses, including taxes, loan repayments, etc.) must be positive. In the event of negative returns the company could become bankrupt. Thus, this is the second criterion that has to be fulfilled in order for the private sector to invest.

On the other hand, the private sector aiming at maximizing its profits, will seek the maximum participation of public sector. Hence an upper limit for public subsidies has to be introduced, as a percentage of the total value of the investment, termed $p_{1}$. In addition, bank loans are not of unlimited amounts and as such, they need to be constrained to a maximum value, determined by the market, and on percentage basis being $1-p_{1}-p_{2}$, where $p_{2}$ is the percentage of private funds (equity). In addition, the required repayment period is negotiable between the bank and the private investor, and thus there is no fixed a priori value [20].

Thus for total investment $\operatorname{costs} C_{m}$, the different sources of capital are:

$$
C_{m}=p_{1} \times C_{m}+p_{2} \times C_{m}+\left(1-p_{1}-p_{2}\right) \times C_{m} .
$$

Any private investment into an infrastructure project has risk implications. To compensate for such risks, the public funds are necessary to minimize the exposure of private funds. However, if the project proves successful, this will result in potential windfall gains for the private investor, their value depending on the amount of public funds. In addition, if with another arrangement, 
the private investor is allowed to adjust prices (and thus increase revenue) due to inflation, this might result in further windfall profit gains.

\subsection{Fixed costs}

The fixed costs make the Freight village operational and include costs associated with the construction, such as the land acquisition, the construction related expenses and the equipment acquisition costs. They are included for the year they are occurring. In general the construction costs are a function of the Logistics centre size. Thus, at the unit price, the total construction costs could be estimated:

$$
C_{m}=f_{1}(S),
$$

where: $S$ - the surface of the Logistics centre.

Also, in the fixed costs, the loan payments are included on an annual basis. In addition, the fixed costs could include:

- $\quad$ provisions for initial expenses overruns and unforeseen expenses (intangibles) during the construction stage;

- funds necessary for miscellaneous expenses and consumables during the first period of operations, as well as insurance premiums during construction [20].

\subsection{Variable costs}

As variable costs, the operational costs of the Logistics centre are considered, such as staff salaries, maintenance, electricity costs, water consumption, telecommunications, insurance of the Logistics centre (building, equipment, etc.), as well as miscellaneous expenses.

The staff salaries depend on the number of employees and the level of salaries, according to the staff specialization. There is a category with permanent staff, and another one with temporary staff. The latter depends on the traffic volumes of the Logistics centre and/or the opening hours. To simplify the method, it is worth to distinguish four categories of salaries:

- category A: high salary (managerial);

- category B: high-middle salary (scientific-technological support);

- category C: low-middle salary (technical);

- category D: low salary (handling).

The annual amounts of the four categories are defined according to actual salaries practices and the applicable laws in the specific country. Similarly, the number of shifts necessary for each job category is estimated:

$$
\begin{aligned}
& C_{p}=\sum C_{p a} \times N_{i}+\sum C_{p b} \times N_{j}+ \\
& \sum C_{p c} \times N_{k}+\sum C_{p d} \times N_{l},
\end{aligned}
$$

where: $N_{i}-$ number of jobs and shifts of category A; $N_{j}$ - number of jobs and shifts of category $\mathrm{B} ; N_{k}-$ number of jobs and shifts of category $\mathrm{C} ; N_{l}$ - number of jobs and shifts of category $D ; C_{p a}$ - annual salary for category A, according to prevailing market conditions; $C_{p b}$ - annual salary for category $\mathrm{B}$, according to prevailing market conditions; $C_{p c}-$ annual salary for category $\mathrm{C}$, according to prevailing market conditions; $C_{p d}$ - annual salary for category $D$, according to prevailing market conditions.

Alternatively, if no details of the personnel are available, they can be estimated as a function of the surface of the Logistics centre, based on values from other similar LC:

$$
C_{p}=f_{2}(S) \text {. }
$$

The other variable costs relate to the consumption of energy and the intensity of using various technical infrastructures. To estimate these costs on an annual basis, indicators for the respective consumption are needed, such as average electricity consumption per $\mathrm{m}^{2}$ of floor area of buildings, average water consumption per $\mathrm{m}^{2}$, etc.

For certain services, such as telecommunications, an indicator higher than the market average must be used, since transport and logistics activities use telecommunication services quite intensively. Therefore, the cost $C_{t i}$ for the use of technical infrastructure $i$ is provided by:

$$
C_{t i}=A_{i} \times P_{i} \times S,
$$

where: $A_{i}$ - the yearly average consumption of the service $i$ (e.g. in $\mathrm{kWh}$ for electricity, $\mathrm{m}^{3}$ of water, etc.); $P_{i}$ - the price of the service per unit; $S$ - the surface of the Logistics centre.

Consequently, the total cost for the use of technical infrastructures $C_{t}$ is given by:

$$
C_{t}=\sum C_{t i}
$$

Alternatively, if no details are available, they can be estimated as a function of the surface of the Logistics centre, based on values from other similar Logistics centre, i.e.:

$$
C_{t}=f_{3}(S) \text {. }
$$

In addition, the following items are included in the variable costs: Maintenance $C_{\text {main }}$, and insurance costs $C_{i n s}$. The corresponding annual amount is estimated according to the prevailing market prices, taking into account the floor area of the buildings as well as the total surface of the Logistics centre:

$$
\begin{aligned}
& C_{\text {main }}=f_{4}(S) . \\
& C_{\text {ins }}=f_{5}(S) .
\end{aligned}
$$

Thus, the total yearly variable costs are:

$$
C_{v}=C_{t}+C_{\text {main }}+C_{\text {ins }} \text {. }
$$

For the first year, the total expenses also include a cost item related to start-up costs (when no revenues are collected, but operations take place). 


\section{Revenues}

The revenue of a Logistics Centre is expected to be generated by:

- rental of warehouses, storage spaces and offices;

- rental of outdoor spaces for cargo placing;

- concession of the hotel and restaurant exploitation;

- fee on the revenues of the gas station;

- charges for operations of the intermodal transport terminal.

The revenues from renting spaces for food and lodging establishments are calculated according to market prices per $\mathrm{m}^{2}$ of rented space. The rental prices per $\mathrm{m}^{2}$ differ according to the respective operation type in use at the rented space. Hence, they are classified as follows:

- price of conventional storage space;

- price of specialized-temperature control storage spaces;

- price of office buildings;

- price of outdoor spaces.

Consequently, the total yearly revenue from rental $R_{r}$ is:

$$
R_{r}=\sum\left(S_{i} \times P_{r i}\right),
$$

where: $S_{i}$ - the surface of facilities of type $i ; P_{r i}-$ the yearly price for rental of facility of type $i$, currency units per $\mathrm{m}^{2}$.

Alternatively, this can be expressed:

$$
R_{r}=g_{1}(S, P)
$$

where: $P$-the price of the services.

The revenues from the operations of an intermodal terminal constitute one of the most significant sources of income for the Logistics centre. The transhipment from one transport mode to another (e.g. rail/road) is considered as a service offered by the Logistics centre. The relevant revenues on a yearly basis emerge from consideration of the expected traffic of unitized cargo and the applied competitive market prices for transhipment operations. The final calculation per year is also based on the assumption of the average 1,5 movements per loading unit, since one loading unit might need one or two different movements (in the cases of intermediate placing or storage of products).

Consequently, the total annual revenue from the intermodal terminal is:

$$
R_{t}=1.5 \times T_{u} \times P_{t},
$$

where: $T_{u}$ - the expected traffic of unitized cargo in the Logistics centre, in tonnes/year; $P_{t}-$ the charge per crane movement, in monetary units per movement. It is determined by the Logistics centre administration according to the adopted pricing policy.

Alternatively, this can be expressed as:

$$
R_{t}=g_{2}(D, P) \text {, }
$$

where: $D$ - the demand for the specific service; $P$ the price for the service.
The revenues from the gas station are considered as a fee on a percentage basis on the gross revenues of the gas station concessionaire. Furthermore, the average capacity of the trucks fuel tanks and the current price of fuel per litre are considered. Existing practices suggest that $50 \%$ of vehicles are refilled inside the Logistics centre. This is due to the fact that many of the incoming vehicles from close origins will have their fuel tanks full, while the trucks, which carry a cargo from a distant origin or depart for a long journey, will need refilling at the Freight village. Consequently, the total yearly revenues $R_{g}$ from the gas station are calculated by:

$$
R_{g}=z \times T_{r} \times A_{c} \times P_{f} \times e,
$$

where: $T_{r}-$ the annual truck traffic of the Logistics centre, in number of truck vehicles; $A_{c}$ - the tank average capacity of trucks entering the Logistics centre; $P_{f}$ - the fuel price, in currency per litter; $e-$ the applicable fee, to emerge from the Logistics centre pricing policy and negotiations with the concessionaire (as a percentage); $z$ - percentage of number of trucks for refuelling.

Alternatively, this can be expressed as:

$$
R_{g}=g_{3}(D, P) \text {. }
$$

Consequently, the total annual revenues of the Logistics centres are provided by:

$$
R=R_{r}+R_{t}+R_{g} \text {. }
$$

\section{Conclusions}

The evaluation methodology, developed in this article is a specific tool, which can be integrated into a wider methodology for planning and evaluating investments in a new Logistics centre, when a mix of public and private funds exists.

Four stages are distinguished, namely (a) site selection and traffic forecasts, (b) definition of services offered and corresponding dimensions, (c) estimation of investment and operation costs and (d) the evaluation. The elaborated financial evaluation model optimizes the possible funding scenarios for the private sector. It allows maximizing the return on investment of private funds, given for the total investment needed. Finally, the model tests the attractiveness (with the calculated IRR) for a private investment in a new $\mathrm{LC}$, in relation to other available opportunities in the market.

The identification of the variable and fixed cash flow items (expenses and revenues) for the particular case of LC is a significant contribution to the development of the evaluation model.

Moreover, the wider planning methodology is structured in such a way, so as to minimize needs for additional data input.

More concretely, most of the data needed for the application of the financial evaluation model are derived from the traffic forecasts. Traffic data is the key variable that determines the services to be offered by a 
Freight village, as well as their dimensioning, which in turn defines most of the fixed and variable costs, as well as the expected revenues.

This article shows that an easily to be applied evaluation method with the corresponding models has been developed specifically for Freight villages. The unique features and characteristics of the LC as a transport infrastructure project, makes it different from road and rail projects, and therefore a specific method is necessary.

\section{References}

1. PAL ̌́AITIS, R. Logistics centers and transit transport interfaces in Lithuania. In Scientific Proceedings of Riga Technical University. Economics and Business. Business and Management. Riga, 2004, p. 83-88.

2. PALŠAITIS, R. Logistics centers influence on economical development of the region. In Conference Proceedings. Development of Logistics, Transport and Communication Services in the Baltic Sea Region. International Conference. Vilnius, 2004, p. 21-26.

3. Synthesis Report. FV 2000. Research Project, European Commission, Brussels, 1999.

4. Logistics centres directions for use. EUROPLATFORMS EEIG. Brussels, 2004, p. 40.

5. JOHANEESSEN, S.; SOLEM O. Logistics organizations: ideologies, principles and practice. The International Journal of Logistics Management, 2002, Vol 13, No 1, p. 8-16.

6. New generation terminal and terminal node concepts in Europe. TERMINET Research Project, European Commission, Brussels, 1997, p. 160.

7. European Commission. Communication from the European Commission of public private partnerships of Trans-European networks projects. Brussels, 1997, p. 80 .

8. Reassessment of the feasibility study for the creation of a national freight village in Peraeus, Mentor Programme, European Commission, Brussels, 1996, p. 120.

9. KONINGS, J. W. Integrated centres for the transhipment, storage, collection, distribution of goods. Transport Policy, 1994, Vol III, No 1/2, p. 3-11.

10. European Commission. Communication from the European Commission of public - private partnerships of Trans-European networks projects. Brussels, 1997, p. 60.

11. MOLES, P.; WILLIAMS, D. Privately funded infrastructure in the UK: participants' risk in the Skye Bridge project. Transport Policy, 1995, Vol 2, No 2, p. 129 134.

12. The PROFIT Methodology. PROFIT Research Project, European Commission, Brussels, 2000, p. 140.

13. YE, S.; TIONG, R. L. NPV-risk method in infrastructure project investment evaluation. Journal of Construction Engineering and Management, 2000, ASCE 126, No 3, p. 227-233.

14. Innovations in decision analysis for transport initiatives. EUNET, Research project, European Commission, Brussels, 1998, p. 140.

15. Transhipment systems description and analysis. IMPULSE Research Project, European Commission, Brussels, 1998, p. 110.
16. Logistics centres in Lithuania: analysis of birth processes. Transport Research Institute (TRI), Vilnius Gediminas Technical University, Lithuania. Networking logistics centres in the Baltic Sea Region (NeLoC). BSR Interreg IIIB, 2003, p. 60.

17. Quality of terminals. IQ Research Project, European Commission, Brussels, 1998, p. 120.

18. TSAMBOULAS, D.; DIMITROPOULOS, J. Appraisal of investments in European nodal centres for goods: a comparative analysis. Transportation, 1999, Vol 33, p. 141-156.

19. Cost-benefit and multi-criteria analysis for new transport infrastructure in the field of nodal centres for goods. EURET, Study, European Commission, Brussels, 1995, p. 140.

20. TSAMBOULAS, D.; KAPROS, S. Freight village evaluation under uncertainty with public and private financing. Transport Policy, 2003, Vol 10, No 2, p. 141-156. 